\title{
THE ADRENAL CORTEX
}

Based on a Panel Discussion ${ }^{1}$ with Gondon M. Wyant, F.F.A.R.c.s., ${ }^{2}$ Moderator; A. J. LONGMORE, F.R.C.P.(c), ${ }^{8}$ and C. H. WeDER, F.R.C.S.(c), ${ }^{4}$ Members

THE IMPORTANCE of the adrenal cortex in healih and disease has been increasingly realized in recent years. The recognition, isolation and synthesis of some of its hormones have made possible the successful treatment of a number of disease states which previously had not been amenable to s secific therapy. The relationship of certain diseases and disease syndromes to tue adrenal cortex which had not been suspected before has now been clarified and this has allowed these conditions to be attacked on a rational and specific basis. Some of these diseases are of importance to the anaesthetist who must, therefore, have a working acquaintance with the physiology and pathology of the adrenal gland and the adrenal cortex in particular. It would, therefore, seem proper at this time to attempt a description of some of the known data on this subject, keeping in mind that it is a field which in many respects is as yet only partly understood, and that much of our present knowledge requires further elucidation or rectification. We shall limit this presentation in the main to a description of adrenal cortical bypofunction.

\section{Physiology}

The secretion of adrenal cortical hormone is regulated by the stumulation of ACTH produced by the anterior lobe of the pituitary gland. This in turn receives its stimulus from the hypothalamus. The resulting stimulation of the adrenal cortex produces the hydrocortisone which circulates in the blood and acts on all the tissues of the body (Fig. 1).

The production of this adrenal cortical hormone is regulated by two factors: (a) One is the amount of circulating corticoid. When this exceeds the amount required, the corticoid inhibits the pituitary from stimulating the adrenal cortex further. In conditions where the tissue need is great and where large amounts of circulating corticoid are used up, its level drops, thus inducing tae pituitary to stimulate the adrenal cortex by producing more ACTH. In turn, if a patient is given cortisone as a medication, the level of circulating corticoid will be raised, inhibiting the pituitary; the production of ACTH will stop and consequently the adrenals will cease producing adrenal cortical hormone and become atrophic. In these cases there is potential danger if the exogenous cortisone is stopped, or if surgery is undertaken without realizing that the adrenal cortex is no longer active and that extrinsic support is required. (b) The

1Presented at the Annual Meeting of the Canadian Anaesthetists' Society, Saskatoon, Sask., June 24-26, 1957.

2Professor and Head, Department of Anaesthesia, University of Saskatchewan College of Medicine and University Hospital, Saskatoon, Sask.

'Chief, Section of Internal Medicine, Regina Genes al Hospital, Regina, Sask.

¿Clinical Associate, Department of Surgery, University of Saskatchewan, College of Medicine, Saskatoon, Sask.

Can. Anaes. Soc. J., vol. 5, no. 1, January, 1958 


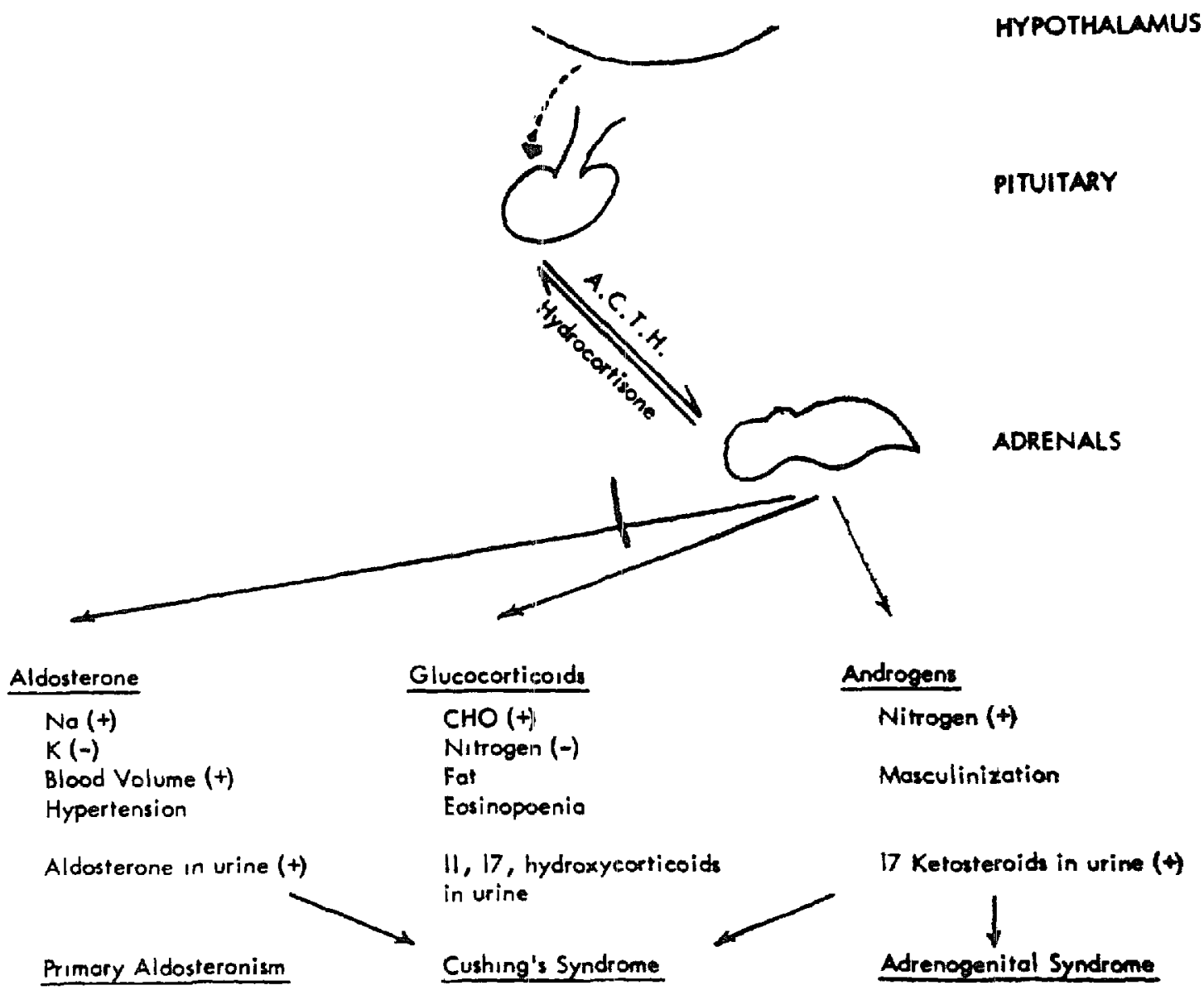

EXCESS ADRENOCORTICAL HORMONES AND DISEASE STATES

(+) - inçrease

$(-)$ - decrease

Figure 1

adrenal cortical output is also controlled by a central stimulus which acts on the hypothalamus. Variations in the intensity of this stimulus alter the amount of adrenal cortical hormones. In the morning a peak is reached and there is a lessening of output in the early evening and night. The production of cortisone by the adrenal cortex parallels that of cellular activity. In this connection it may be of interest to note that in Graves' disease, where cellular activity is high, the amount of adrenal cortical hormones necessary to maintain the body welfare is higher than normal. The role of the cortex is one of supjort rather than one of initiating action. The effectiveness of the hormone will cepend on the state of the cells with regard to oxygenation and food supply. The gluco-corticoid portion of the adrenal cortex secretions has an anti-inflammatory effect, which may inhibit fibroblastic proliferation and thus retard healing.

\section{Stress}

It is well known that adrenalectomized animals or those with ineffective adrenal cortices withstand surgery and trauma poorly. This fact is corroborated by the 
poor response to these stresses made by the patient with Addison's disease. Under normal conditions of stress, stmull by the pituitary lead to an increased production of adrenal cortical hormone In patients with severe burns or in irreversible shock the general body deterioration has sometırnes been attributed to exhaustion of the adrenal cortex or its stimulating gland, the pitutary. This clinical impression was borne out by the good effect that supportive exogenous cortisone had when used to sustain patients who seemed to have deteriorated. We do know that adrenal cortical hormone of endogenous and exogenous nature does help to maintain the patient in severe stress. The mechanism by which this occurs is not so clear and some of the effects of the hormone even appear to be deleterious. It has been suggested that the hormone may detoxify some of the noxious substances produced by the stress on the cells, these noxious substances may be histamirielike chemicals. The effect on the cardrovascular system appears to be that of twining, and when the adrenal cortical hormone is completely absent, there is an "arteriolar asthenia" This is manifested by a loss of vascular tone and an increase in capillary permeability. The arteriole has lost its responsiveness to the ordinary circulating vasoconstrictor elements, producing a loss of crrculating blood volume, and a diminution of the extracellular fluid space In ordinary stress the amount of circulating cortical hormones returns to normal on the third or fourth day.

\section{Medical Conditions}

Adrenal cortical insufficiency is a comprehensive term denoting deficiency of one or more of the adrenal cortical hormones essential to homeostasis. This deficiency can be classified as

1. Primary

(a) Adrenal destruction tuberculous, 70-50\%, 5 neoplastic, 5-10\% (secondary), acute-overwhelming infection with toxaemia (Waterhouse-Friderichsen Syndrome. ${ }^{6}$

(b) Primary adrenal atrophy, 30-50\% (becoming more common as T.B. becomes less)

2. Secondary

(a) Deficient ACTH from pituitary.

(b) Administration of steroids.

Adrenal cortical insufficiency may occur acutely and unexpectedly $(a)$ when a

5

Addison

Guttman

Rowntree and Snell

Barker

Coneybeare and Mills

Wells

Duffin

Soffer et al.

Snell (1934): "incidence of atrophy as a cause was increasing"

${ }^{6}$ Two hundred cases in literature to date rare, common in children under five

Martland (1944) 19 cases in 10,000 autopsies over 13 years-10 in children under 5, 9 in adults 
patient is subjected to anaesthesia and surgery, having previously been in a subclinical state of insufficiency, $(b)$ in the course of severe and overwhelming infections; $(c)$ during operation or postoperatively in those pattents who have received steroids in the recent or distant past, when the sterolds have suddenly been withdrawn. Steroid therapy has been used with varying success in a multtude of conditions. A mong these are.

1. Adrenal atroshy

2. Addiction-crugs, alcohol

3. Asthma

4. Blood dyscrasıas leukaemıas, haemolytic anaemıas, thombopoenıas, primary and secondary

5. Dermatitis

6. Burns

7 "Collagen diseases". rheumatic fever, rheumatic arthritıs, polyarteritis, lupus, scleroderma, dermatomyositss.

8 Hepatitis

9. Nephrosis

10. Mumps: orchtts, oophorits, pancreatitss

11. Overwhelming bacteraemia

12. Pulmonary fibrosis

13. Sarcoidosis

14. Trichinosis

15. Intestinal dysfunction- "mal absorption syndrome"

16 Shock (non-haemorrhagic)

17 Ophthalmological disorders

In obtaining a pre-anaesthetic history, it is advisable to question patients about suffering from any of these disorders, and to ask directly if they have been receiving "hormones" Many patients know the exact drug and dosage. We now know that the patients may not have regained full cortical function as much as one to two months after steroids have been discontinued Periods of up to two years have been suggested by some authoritues

Lastly, a patient may have classical Addıson's disease This disease, although rare, is more common than realized Soffer reports an incidence of 1 case per 4,500 hospitad admissions. The classical picture is one of insidious onset and steady progression, of asthenu, loss of weight, anorexia with nausea and vomiting, and constipation-or abdominal cramps with diarrhoea There is a "sun-tan" pigmentation of specific areas, exposed surfaces, flexor creases, buccal mucosa and genitalia, with anaemia, hypotension and susceptibility to infection. There is impotence and loss of libido in the male, amenorrhoea in the female, and irritability with personality changes

\section{Tests for Adrenal Function}

1. Cutler-Power-Wilder Test on constant intake of sodum, potassium and chlorme, there is excessive urme loss of chlorine ${ }^{7}$

7(1) $95 \mathrm{gm} . \mathrm{NaCl}$ and $41 \mathrm{gm}$ potassium per day, in measured diet, (2) after first day, and on morning of second day, $42 \mathrm{mg}$ of potassium citrate per pound of body weight, with water as desired, (3) after this ingested, fluid 15 limited to $40 \mathrm{cc}$ per $\mathrm{kg}$ on second day, (4) on third day, fluid to $20 \mathrm{cc}$ per $\mathrm{kg}$ untll $1100 \mathrm{~A} \mathrm{M}$, (5) unne is collected from $800 \mathrm{P} \mathrm{M}$. on second day until $800 \mathrm{AM}$ of third, and from $800 \mathrm{AM}$ until noon of throd day. This is analysed for quantity of chloride normal 15 17-141 mg 署 (average-54), Addison, 229-356 mg $\%$ (average-290) 
2. Robinson-Kepler-Power Water Test: $1500 \mathrm{ml}$. water is drunk in $\mathbf{4 5}$ minutes. The normal patient excretes $800 \mathrm{ml}$. or more urine in 5 hours; the "Addison" patient excretes less than $800 \mathrm{ml}$.

3. Determination of (a) 17-keto-steroids, (b) 11-oxy-steroids, in urine ${ }^{8}$ before and after stimulation by ACTH-25-30 units intramuscularly.

4. Glucose Tolerance Test: orally or intravenously.

5. Thorn Test: after $20-25 \mathrm{mg}$. ACTH is injected intramuscularly, the eosinophil count falls after 4 hours by 50 per cent or over.

\section{Treatment of Adrenal Cortical Insufficiency}

For clinical surposes, we have in treatment:

1. Salt: Orcinary diet; 6-8 gm. per day; may need to add another 1-2 gm.

2. Desoxycorticosterone acetate: (a) In sesame oil for intramuscular use; $(b)$ as aqueous percorten glucoside for intravenous use; $(c)$ trimethylacetate for intramuscular use (an ester in micro-crystalline suspension-lasts 4-6 weeks); (d) pellets for implantation; (e) DOCA in propylene glycol-sublingual.

3. Cortisone and hydrocortisone: cortisone, $25-50 \mathrm{mg}$. per day; hydrocortisone, $20-40 \mathrm{~m}$. per day.

4. Alp ra-9-fluorohydrocortisone: $.25-.5 \mathrm{mg}$. per day.

5. Aldosterone: $1 \mathrm{mg}$. (orally or intramuscularly) $2-3$ per day.

6. Whole adrenal cortical extract: expensive, uncomfortable.

7. Combinations of above.

8. Best regimen seems to be (a) full diet and extra salt if necessary, $(b)$ daily oral dose of one-commonest 3,4 or 5 above; $(c)$ one of DOCA compounds intramuscular every 1-6 weeks as needed; (d) patients should carry a card with name, address, diagnosis and above dosages in detail.

\section{Complications of Tizeatment}

1. Congestive heart failure.

2. Myocardial infarction.

3. Hypertension.

4. Spread of infection-unrecognized.

Determination of $(a)$ 17-keto-steroids in urine-normal varies according to age and sex, with a wide range in any one group.

$\begin{array}{lc} & M g . / 24 \\ \text { To age } 7 & 1.3 \\ 7-12 & 4.0 \\ 12-15 & 8.2 \\ \text { Adult male } & 15.0 \\ \text { Adult female } & 10.2\end{array}$

Alpha comprise 85-90\%, beta comprise 15-10\%; beta fraction markedly increased in cortical carcinoma.

Determination of $(b)$ 11-oxy-steroids in urine-normal range vanes in different laboratories and with method used. (1) colorimetric (Talbot)-.12-.34 nag./24 hr.; (2) periodic oxidation and measurement of formaldehyde liberated: Daughaday-1.0-2.0 mg./24 hr.; Soffer-0.5i-2.0 mg./24 hr. 
5. Perforation of viscus-pre-existing ulcer or spontaneous.

6. Gastro-intestinal haemorrhage.

7. Psychosis.

8. Spontaneous fracture.

9. Adrenal cortical atrophy (does not occur following ACTH therapy).

10. Hyperglycaemia (aggravated by pre-existing diabetes mellitus).

\section{Relative Contrandications to Adrenal Corttcal Therapy}

1. Active tuberculosis: pulmonary, osseous, renal (now all right with antibiotic coverage-streptomycin +PAS, or streptomycin+INH).

2. Peptic ulcer: ulcer régime-diet, alkali, anti-spasmodic, etc.

3. Chronic renal disease.

4. Congestive heart failure.

5. Myasthenia gravis.

6. Psychosis.

7. Hypertension.

8. Diabetes mellitus.

9. Osteoporosis.

10. "Emotional lability."

11. Hirsutism in the female.

12. Surgery.

\section{Surgerpy of the Adrenal Gland}

The surgeon's interest in the adrenal cortex is twofold. First, he is interested in those diseases which attack the adrenal glands or those conditions in which the removal of the adrenal glands may affect other diseases of the body such as secondary carcinoma of the sreast. Secondly, he is interested in the normal role of the adrenal cortex in such conditions as shock, peptic ulceration, the healing of wounds, the use of homografts and the effect on the inflammatory process.

There are four diseases or conditions in which surgery is used to remove one or both adrenals (1) secondary carcinoma of the breast; (2) unilateral or bilateral non-endocrine tumours of the adrenals; (3) tumours of adjacent organs such as the kidney; (4) abnormal conditions of adrenal function which are manifested by a hypersecretion of the adrenal cortical hormone.

In the first three groups it is necessary to supplement the normal adrenal cortical hormone by substitution therapy. In carcinoma of the breast, it is particularly advisable to do this, even if the adrenals are being removed in two stages, because it has been found that in at least a third of the cases, after one gland has been removed, the remaining adrenal has been afflicted with secondary carcinoma and thus its function is impaired. With the removal of non-endocrine tumours or adjacent tumours involving the adrenal, supplemental therapy is wise as a precautionary measure. This is especially true in phaeochromocytoma where the tumour is often bilateral and malignant. While the cortex is not the site of the tumour, and is not by itself hypersecreting, it invariably has to be removed to eradicate the medullary tumour. 
Hyperfunctioning conditions of the adrenals The basis of this hypersecretion may be secondary to some other stimulation, presumably that of the pituitary, or it may be due to an independently functioning tumour. Adrenal cortical over-activity may manifest itself in a variety of clinical syndromes

The first and most recently discovered is that of primary aldosteronism in which there is a retention of serum sodium and water, a depression of potassium with secondary hypertension In advanced cases, alkalosis, periodic paralysis, tetany and polyuria are apparent This condition is almost invariably due to tumour Temporary and decreasing corticold cover is wise after its removal to prevent a too rapid return to a normal endocrine pattern The dosage here however would be given intravenously, as needed, rather than as a heavy intramuscular medication which is not too readily controllable

The second condition is Cushing's syndrome in which there is excess of glucocorticords, the androgenic corticonds, as well as the electrolyte effect in variable proportion The anaesthetist has to contend with hypertension, the bullneck obesity with its aurway difficulties as well as with the problem of hormone management durng operation. If the disease is due to a unilateral tumour, the blood serum has been flooded with an excess of gluco-corticoids which has acted, through the pituitary, to depress the other adrencl On removal of the adrenal tumour the patient is then left in an "Addisonian" condition and must be supported with intravenous cortıcoid therapy. If a preoperatıve diagnosis is made, intramuscular corticold support on the two days previous to operation would be advisable to form a cushion for the intravenous supplement When Cushing's disease is due to hyperplusia, supplemental therapy is necessary of both adrenals are completely removed or if a subtotal adrenalectomy is done because of the difficulty in assessing both the amount of adrenal which remains behind and the efficiency with which this remnant may function

The third condition of hyperfunction of the adrenal cortex for which surgery is sometımes done is the adreno-genital syndrome which, like Cushing's syndrome, may be due either to tumour or to secondary hyperfunction In this condition the problem is quite similar to that in Cushing's disease.

Recently workers have been dong total adrenalectomes for certan types of malignant hypertension and the problem here is simply one of supplemental therapy

\section{Anaesthetic Considerations}

Reference has been made in previous paragraphs to the importance of detelmuning from the patient's history whether cortical steroids have been administered previously and, if they have, of remstituting cortisone therapy preoperatively. Prophylactic adminstration of cortisone is also required for all operations on the adrenals or in cases where removal of one or both glands is contemplated. Patients who are actually on steroid therapy should have the dosage increased before operation

The aforementioned indications for adrenal steroıd therapy are quite straight forward The only questions are how much hormone should be given pre- 
operatively, and how long after cessation of therapy it is safe to dispense with prophylactic medication, when performing such an operation.

A dosage of 100 to $150 \mathrm{mg}$ of cortisone per day orally for two or three days preceding operation and a further intramuscular dose on the morning of operation would seem adequate for most patients except those who are on sterord therapy, for whom it is just a matter of increasing the maintenance dose Hydrocortisone, prednisone or prednisolone may be ùsed in place of cortisone.

The question as to how long after previous therapy it is safe to operate without 1esuming hormone substitution is still controversial. Some authorities insist that in some patients there is residual latent adrenal insufficiency for many years. Today, with rapid acting intravenous steroıd preparations available, this question is more academic than real, since, if such imparment of adrenal function persists, and becomes clinically manifest in the course of operation, immediate administration of intravenous aqueous hydrocortone will avold difficulties. It would therefore seem reasonable to set an arbitrary limit of two years, being fully cognizant that in an occasional case this may be too short a period

\section{LATENT AdRenal INSUfFiciency}

This condition is not infrequently encountered in chronica ly ill patients, often suffering from advanced malignancies, or other chronic debilitating conditions, who are undergoing prolonged or radical operations. These individuals have usually lost weight, have poor skun turgor, look haggard and may be assumed to have a restricted circulating blood volume The clnical picture consists essentially of progressive hypotension accompanied or not by increasing tachycardia, pallor, perspiratiop, and possibly aur hunger, although these symptoms are neither as constant nor as pronounced as in oligaemic shock. The syndrome commonly appears $1 n$ or after the second hour of operation and not infrequently supervenes after completion of the surgical procedure It does not respond to vigorous blood and fluid replacement or to the administration of potent vasopressors which are ineffective or have a fleetıng effect only, even if administered as an intravenous infusion. The condition is not reflex in origin and does not respond to the administration of atropine in large doses If untreated the condition is progressive and the patient may die despite heroic measures. Experience has shown that these patients do respond, however, to prompt treatment with intravenous hydrocortisone. With experience, one is soon able to anticipate many of these cases, it is then wise to start sterond therapy before difficulties arise. Hydrocortisone $100 \mathrm{mg}$ is administered intravenously every four hours during operation, or if hypotension is already present it may be given more frequently untıl an adequate blood pressure has been restored. Administration is reduced to three times daily on the first postoperative day, twice daily on the second postoperative day, and one last injection is given on the following day, if the patient is able to maintain adequate homeostasis on this regimen of weaning. If hypotension recurs, the daily dose is increased again. Massive but short-lasting medication of this type does not seem to influence adrenal activity to the point where the patient becomes permanently dependent upon substitution therapy. Nor, in our experience, does 
it seem to interfere with wound healing. We have observed no evidence of electrolyte imbalance, but we are routinely opposed to the administration of sodium chloride solutions for the first two postoperative days if there was no pre-existing electrolyte imbalance, and hence the question of sodium retention does not arise.

It is of course true that hydrocortisone in itself has no vasopressor activity; at least we have failed to show any such activity in normotensive human beings. It has been postulated that cortisone conditions the metarterioles to the action of endogenous epinephrine and there is some good experimental evidence to support this view. However, it seems that at least in normal individuals, no correlation can be established between the action of hydrocortisone and epinephrine; in experiments conducted on human volunteers we have been unable to establish any such correlation. These volunteers were given one millilitre of norepinephrine 0.0002 per cent intravenously, and pulse and blood pressure responses were observed and recorded There was usually an immediate peak pressure response which gradually returned to pre-experiment levels in about thirty minutes. Several hours later, hydrocortisone $100 \mathrm{mg}$ was administered intravenously followed by hourly eosinophil counts. When the eosinophil count had fallen to approximately 50 per cent of the pre-experiment level, the same amount of norepinephrine was again administered and blood pressure and pulse responses again noted In no case was a subsequent hypertension greater or more prolonged than in the control experment. This seemed to indicate that in healthy and normotensive individuals at least, a peak effect of vasoconstriction is obtained by norepinephrine alone and is not potentrated by the previous administration of cortical steroids.

Sandberg found that general anaesthesia was followed by an increase in steroid concentration in eight of twelve patients. In twenty-two patients, eleven of them with malignant disease, Virtue has recently reported that dihydroxycorticosteroids uncreased on the average from 11 gamma per cent to 25 gamma per cent after one hour, and 34 gamma per cent after three hours of operation. There was no significant difference for patients with non-malignant and malignant disease. However, this observation does not materially assist the argument that some cases of hypotension may be due to adreno-cortical insufficiency since $(a)$ steroid blood levels do not tell the whole tale of adrenal function, and (b) more important still, none of Vurtue's malignant cases showed shock. A very large series of cases would be necessary in order to include a sufficient number of "adrenal shock" to be able to compare them with those who do not exhibit this phenomenon. This would be an undertaking of considerable magnitude.

It would seem reasonable to formuate a concept that in severely and chromcally ill patients one deals with a state of borderline adrenal function. Thus, adrenal function is adequate in these individuals to take care of the daily needs and stresses which in these particular patients are not very great as a rule. When great stress is imposed, their adrenal function is inadequate to deal with it and relative adrenal insufficiency develops. As soon as, after a few days, the peak stress has disappeared, adrenal function is again adequate to cope with an uncomplicated normal convalescence. It has been found experimentally in adrena- 
lectimized animals that in the phase of severe stress the substitution therapy which was adequate for these animals under normal conditions becomes inadequate and this has been termed "relative cortisone deficiency." It seems eminently reasonable that a similar state of affairs could obtain in some types of patient. Burstein has recently described a short bedside test to determine adrenal function by estimating the sodium concentration in plasma and urine by means of a flame photometer. In adrenal cortical insufficiency there is significant reduction in the serum sodium concentration (less than $130 \mathrm{mEq}$./litre) and a higher excretion of sodium in the urine (more than $100 \mathrm{mEq}$./litre). It has been found that during general anaesthesia, and in the absence of an excitement stage, there is an increase of 17-hydroxycorlicosteroids in the plasma with a normal eosinophil count. This combination is difficult to explain unless one surmises that the disturbances of liver and kidney function during general anaesthesia interfere with the usual conjugation and excretion of the adreno-cortical steroids, resulting in a disturbance $o$ " the balance between their secretion and utilization on the one hand, and destruction and excretion on the other.

Premedicant drugs seem to have a certain influence on adreno-cortical function, mainly through the pituitary-adrenal axis. Thus morphine causes diminution of secretion of ACTH by the pituitary resulting in depressed adreno-cortical function. The same effect has been shown for pentobarbital. Administration of therapeutic doses of pentobarbital produces a significant fall in the free serum corticoid level from twelve to six micrograms. However, subsequent intravenous administration of ACTH resullts in the usual rise of corticoids which seems to soint to a depression of the formation of ACTH, Jossibly by means of an altered sypothalmic threshold. Psychic stress from appresension and anxiety in the preoperative period is also imjortant. In healthy subjects, it has been shown that urinary secretion of 17-hyc roxycorticosteroids rises from a mean level of 1-4 micrograms per minute to 5.6-8.3 micrograms when feelings of apprehension, anger or excitement are jresent. On the other hand, the over-all effect of anaesthesia on adreno-cortica function would seem to be a blockade of traumatic stimuli. A number of clinical reports have shown that adreno-cortical insufficiency due to surgical trauma can appear when anaesthesia is ended.

Untal all these problems are adequately elucidated it seems wise to agree with Burstem who recommends that "whenever there develops a condition of shock which is not due to manipulative circulatory reflexes and which does not respond to adequate blood replacement, the patient should be given the benefit of the doubt and should be treated with intravenous hydrocortisone."

\section{SUMMarY}

This presentation has attempted to summarize the role of the adrenal cortex in health and disease. The medical conditions for which cortisone therapy has been employed have been listed, in order to alert the anaesthetist to the possibility of previous treatment with steroids in patients who are suffering or have suffered at any time from these diseases. The various tests for adrenal function are described, as are the treatment of adrenal cortical dysfunction, the complications of treatment, and contra-indications to steroid therapy 
The adrenals may be removed by the surgeon. (1) to mfluence secondary carcinoma; (2) to remove non-endocrine tumours of the adrenals, (3) to influence abnormal conditions of adrenal function manifested by hypersecretion of adrena] cortical hormones, (4) incidentally, in the course of operations on adjacent organs. In all these cases substitution therapy is necessary It should be started preoperatıvely and may have to be carried on indefinitely

Finally, the condition of "latent adrenal insufficiency" is described. This is a syndrome characterized by a shock-like state following major stress It responds poorly to the usual measures adopted for shock, but is often dramatically in. fluenced by the administration of large doses of adrenal cortical hormone Prophylactic use of steroid therapy in suspect cases is advocated

\section{RÉSUMÉ}

Dans cet artıcle, nous avons ess.lyé de résumer le rôle du cortex surrénalıen dans l'état de santé et au cours de la maladie Nous avons énuméré les états pathologiques où l'on a employé la cortısone de façon à attırer l'attention de lanesthésiste sur la possibilité d'un trattement antérieur aux stéroides chez des malades qui souftrent ou ont déjà souffert de ces maladies Nous avons décrit les dufférentes épreuves de la fonction surrénalıenne annsı que le traitement des troubles corticaux surrénaliens, les complications du trattement et les contremdications de cette thérupie

On peut enlever chrurgicalement les surrénales. (1) pour agur sur un carcinome secondarre, (9) pour enlever des tumeurs non endocrmennes de la surrénale, (3) pour modifier des états anormaux de la fonction surrénalienne manufestés par une hypersécrétion d'hormones corticales, (4) incidemment, au cours d'opérations sur les organes voisıns Dans toutes ces éventualités, il faut instituer une thérapie de substitution Il serait préférable de ld commencer avant l'opération et il peut arriver qu'on doive la continuer indéfinıment

Enfin, nous avons décrit l'état d'insuffisance surrénalıenne chronique. Il s'agit d'un syndrome caractérisé par une sorte d'état de choc à lia suite d'un stress important On obtient peu de réponse aux tratements usuels du choc, mais il répond souvent, de façon étonnante, à l'admmistration de fortes doses d'hormones cortıcales surrénalıennes Dans les cas douteux, il est même conselllé d'instituer une thérapie prophylactıque aux stérordes 